Research Article

\title{
Capillary Water Absorption Characteristics of Recycled Concrete in Freeze-Thaw Environment
}

\author{
Qianhui Xiao, Xiaolin Liu (D), Jisheng Qiu, and Yangyang Li \\ College of Architecture and Civil Engineering, Xi'an University of Science and Technology, Xi'an 710054, China \\ Correspondence should be addressed to Xiaolin Liu; 18204209052@stu.xust.edu.cn
}

Received 1 March 2020; Revised 7 April 2020; Accepted 11 April 2020; Published 7 May 2020

Academic Editor: Dora Foti

Copyright ( 2020 Qianhui Xiao et al. This is an open access article distributed under the Creative Commons Attribution License, which permits unrestricted use, distribution, and reproduction in any medium, provided the original work is properly cited.

In order to study the capillary water absorption characteristics of recycled concrete (RAC) with different replacement rates of recycled coarse aggregate $(0,20 \%, 40 \%$, and $60 \%)$ in freeze-thaw environment, the standard test method of measuring the water absorption of hydraulic cement concrete (ASTM C1585-13) was adopted, and the influence mechanism of freeze-thaw cycle and replacement rate of recycled coarse aggregate on the capillary water absorption of RAC was analyzed, and a prediction model of initial capillary water absorption of RAC in freeze-thaw environment was established. The results show that when the freeze-thaw environment is the same, the greater the replacement rate of recycled coarse aggregate, the greater the cumulative water absorption of RAC, the faster the initial capillary water absorption, and the stronger the capillary water absorption; when the freezethaw environment is different, the more the freeze-thaw cycles, the greater the cumulative water absorption of RAC with the same replacement rate of recycled coarse aggregate, the faster the initial capillary water absorption, and the stronger the capillary water absorption. The prediction model of RAC initial capillary water absorption established by regression analysis has high accuracy, which can be used to predict RAC capillary water absorption performance and provide theoretical basis for the research of RAC frost resistance durability.

\section{Introduction}

Since the reform and opening up, China's economy has continued to develop at a high speed, and the construction industry as a pillar industry has made great achievements. At the same time, the large-scale infrastructure construction also pays a huge cost of resources and environment. According to statistics, the use of concrete in China accounts for $45 \%$ of the total use in the world, and it is estimated that the output of domestic construction waste will reach an amazing 3.966 billion tons by 2020 . Such a huge amount of construction waste is mainly disposed by traditional methods such as stacking or landfill. It has polluted the air, soil, and groundwater, increased the difficulty of urban governance, and damaged the image of the city, which is a big problem faced by city managers. At present, the recycling of resources has become a global hot spot. Many countries actively promote the application of recycled aggregate concrete by introducing relevant policies or encouraging innovation. After crushing, cleaning, and grading the waste concrete blocks in the construction waste, they are mixed to form recycled coarse aggregate in a certain proportion, and the new concrete prepared by partially or completely replacing the natural aggregate is called recycled concrete [1]. It has also been studied that a large number of waste mussel shells from aquaculture and mussel factory residues are partially or completely replaced by natural aggregate to prepare recycled concrete for engineering application, which improves the sustainability of this new type of concrete and the environment [2]. Recycling of recycled concrete is the most effective way to solve the abovementioned problems. The application of recycled concrete technology will form the circular industry development mode of "production-usewaste-reproduction-use of concrete, which can realize the effective recycling and reuse of waste concrete. It is of great significance for environmental protection, resource 
conservation, and the development of ecological buildings. It meets the requirements of sustainable development and is an important development direction of concrete industry in the future.

Concrete is a kind of porous building material, and the transmission of water in porous material is an important reason for its performance degradation [3]. There are three modes of migration of water and water-soluble ions in concrete: diffusion of ions in saturated pore solution, capillary adsorption, and infiltration under pressure gradient [4]. In concrete, capillary action is the main way of water penetration, which has been paid more and more attention by scholars in various countries [5-7]. At present, the water absorption of building materials has been widely used to characterize the water absorption of concrete and gradually become an important index to evaluate the durability of concrete. Scholars at home and abroad have carried out a lot of research on capillary water absorption of ordinary concrete. Qiu et al. [8] analyzed the influence of freeze-thaw damage and polypropylene fiber content on the capillary water absorption performance of gangue concrete and established the initial capillary water absorption model. Ghasemzadeh et al. [9] used the ASTM C1585-13 [10] test method to draw the conclusion that the capillary water absorption increased linearly with the increase of damage degree and tended to be stable in the later stage. Elawady et al. [11] found that the curing conditions have a significant effect on the capillary water absorption of concrete compared with the compressive strength, and the addition of appropriate amount of silica fume can increase the compressive strength of concrete and reduce the capillary water absorption. Foti et al. [12] used blast furnace slag and microsilica or blast furnace slag and fly ash to completely replace sand for the water absorption test. It was found that compared with ordinary concrete, its water absorption rate was lower. The mechanism of water transfer in recycled concrete is mostly limited to the study of permeability and ion diffusion [13-18], and the study of capillary water absorption is less. However, capillary adsorption is not only the main way of water penetration [19] but also the control factor of accelerating concrete deterioration in freeze-thaw environment [20]. Therefore, it is necessary to study the capillary water absorption performance of recycled concrete in freeze-thaw environment.

Based on the capillary water absorption test and freezethaw cycle test, this paper studies the effect of freeze-thaw cycle and recycled coarse aggregate replacement rate on the capillary water absorption of recycled concrete, analyzes the initial capillary water absorption of recycled concrete in different freeze-thaw environments, and establishes the prediction model of the initial capillary water absorption of recycled concrete in the freeze-thaw environment, so as to improve the capillary water absorption of recycled concrete for reference.

\section{Experiment}

2.1. Materials. The cement used is PO $42.5 \mathrm{R}$ cement produced by Shanxi Qinling Cement Co., Ltd., with the basic properties shown in Table 1 and the chemical composition shown in Table 2 . The natural fine aggregate is medium sand, and the natural coarse aggregate (NCA) is continuously graded stone with the particle size of $5-15 \mathrm{~mm}$. The recycled coarse aggregate (RCA) is taken from the waste concrete test block in the laboratory, which is crushed into $5-15 \mathrm{~mm}$ gravel by using a jaw crusher. Before the test, the recycled coarse aggregate and gravel were screened and graded continuously (see Table 3 for each aggregate parameter). The test water is an ordinary tap water. A superplasticizer (SP) and air-entraining agent (AEA) were used in the test.

2.2. Specimen Preparation. Two types of specimens, $100 \mathrm{~mm} \times 100 \mathrm{~mm} \times 100 \mathrm{~mm}$ and $100 \mathrm{~mm} \times 100 \mathrm{~mm} \times$ $400 \mathrm{~mm}$, are required for the test. Among them, the size of the specimen for the compressive strength test and capillary water absorption test is $100 \mathrm{~mm} \times 100 \mathrm{~mm} \times 100 \mathrm{~mm}$, and the size of the specimen for the freeze-thaw damage test is $100 \mathrm{~mm} \times 100 \mathrm{~mm} \times 400 \mathrm{~mm}$. Three specimens are taken as a group. In the design of mix proportion, combined with the characteristics of recycled coarse aggregate itself and meeting the requirements of concrete workability and slump, the water-cement ratio of the recycled concrete is 0.45 , and the replacement rate of the recycled coarse aggregate is $0,20 \%, 40 \%$, and $60 \%$, respectively (see Table 4 for the laboratory mix proportion). Among them, Q0, Q20, $\mathrm{Q} 40$, and Q60 indicate that the replacement rate of recycled coarse aggregate is $0,20 \%, 40 \%$, and $60 \%$, respectively. When making the specimen, the recycled coarse aggregate shall be prewetted first [21], and then the sand, cement, stone, and recycled aggregate shall be put into the forced mixer. After the mixture is evenly mixed, the weighed tap water shall be poured in, and then the mixture shall be stirred for 2-3 min to make the different materials evenly mixed. After mixing evenly, the newly mixed concrete is temporarily poured on the wet iron plate, and then the concrete is, respectively, put into the plastic mold of different sizes. After 24 hours, the test piece is taken out of the mold and put into the standard curing box (temperature $20 \pm 2{ }^{\circ} \mathrm{C}$, relative humidity $95 \%$ ) for 28 days.

\subsection{Test Method}

2.3.1. Freeze-Thaw Cycle Test. The freeze-thaw test shall be conducted according to GB/T 50082-2009 [22], and the KDR-V9 series concrete rapid freeze-thaw test machine produced by Beijing Shuzhi Yilong Instrument Co., Ltd., shall be used for the freeze-thaw cycle test. Before freezethaw, the test piece is immersed in water for 4 days, and the water surface shall be at least $20 \sim 30 \mathrm{~mm}$ higher than the specimen so that the specimen is in the state of water saturation, and the freeze-thaw test shall be started after the specimen is immersed for 4 days. After 25 freeze-thaw cycles, the $100 \mathrm{~mm} \times 100 \mathrm{~mm} \times 400 \mathrm{~mm}$ test piece is taken out and the mass loss and relative dynamic elastic modulus are measured.

NVL2000B electronic balance is used to measure the mass loss, the test block is taken out from the freeze-thaw 
TABle 1: Cement quality index.

\begin{tabular}{|c|c|c|c|c|c|c|c|c|}
\hline \multirow[t]{2}{*}{ Cement variety } & \multirow{2}{*}{$\begin{array}{c}\text { Fineness } \\
\text { modulus (\%) }\end{array}$} & \multirow{2}{*}{$\begin{array}{c}\text { Standard consistency } \\
\text { water consumption }(\%)\end{array}$} & \multicolumn{2}{|c|}{ Setting time } & \multicolumn{2}{|c|}{$\begin{array}{c}\text { Flexural } \\
\text { strength } \\
(\mathrm{MPa})\end{array}$} & \multicolumn{2}{|c|}{$\begin{array}{c}\text { Compression } \\
\text { strength } \\
(\mathrm{MPa})\end{array}$} \\
\hline & & & $\begin{array}{c}\text { Initial } \\
\text { setting }(\mathrm{min})\end{array}$ & $\begin{array}{c}\text { Final } \\
\text { setting }(\mathrm{h})\end{array}$ & $3 \mathrm{~d}$ & $28 \mathrm{~d}$ & $3 d$ & $28 \mathrm{~d}$ \\
\hline P.O $42.5 \mathrm{R}$ & 3.4 & 26.74 & 65 & 5 & 6.21 & 8.2 & 29.8 & 56 \\
\hline
\end{tabular}

Table 2: Cement chemical composition (mass fraction).

\begin{tabular}{lcccccc}
\hline Chemical composition & $\mathrm{Fe}_{2} \mathrm{O}_{3}(\%)$ & $\mathrm{SiO}_{2}(\%)$ & $\mathrm{MgO}(\%)$ & $\mathrm{SO}_{3}(\%)$ & $\mathrm{Al}_{2} \mathrm{O}_{3}(\%)$ & $\mathrm{CaO}(\%)$ \\
\hline Content & 5.25 & 21.66 & 1.06 & 2.03 & 5.13 & 64.37 \\
\hline
\end{tabular}

TABle 3: Physical properties of aggregate.

\begin{tabular}{lccccccc}
\hline Type of coarse aggregate & Particle size $(\mathrm{mm})$ & $\begin{array}{c}\text { Crushed } \\
\text { index }(\%)\end{array}$ & $\begin{array}{c}\text { Bulk } \\
\text { density }\left(\mathrm{kg} / \mathrm{m}^{3}\right)\end{array}$ & $\begin{array}{c}\text { Fineness } \\
\text { modulus }\end{array}$ & $\begin{array}{c}\text { Water } \\
\text { absorption }(\%)\end{array}$ & $\begin{array}{c}\text { Shape } \\
\text { index }(\%)\end{array}$ & $\begin{array}{c}\text { Apparent } \\
\text { density }\left(\mathrm{kg} / \mathrm{m}^{3}\right)\end{array}$ \\
\hline RCA & $4.7-31.5$ & 11 & 1302 & 3.3 & 3.1 & 13.9 & 2630 \\
NCA & $4.7-31.5$ & 6 & 1435 & 2.7 & 1.3 & 14.5 & 2820 \\
Sand & $0.16-5$ & - & 1480 & 2.7 & 0.2 & - & 2650 \\
\hline
\end{tabular}

TABLE 4: Mix ratio of recycled concrete.

\begin{tabular}{lccccccccc}
\hline Number & Water-cement ratio & $\begin{array}{c}\text { Cement } \\
\left(\mathrm{kg} / \mathrm{m}^{3}\right)\end{array}$ & RCA $\left(\mathrm{kg} / \mathrm{m}^{3}\right)$ & Sand $\left(\mathrm{kg} / \mathrm{m}^{3}\right)$ & $\begin{array}{c}\text { Stone } \\
\left(\mathrm{kg} / \mathrm{m}^{3}\right)\end{array}$ & $\begin{array}{c}\text { Water } \\
\left(\mathrm{kg} / \mathrm{m}^{3}\right)\end{array}$ & $\begin{array}{c}\text { AEA } \\
\left(\mathrm{kg} / \mathrm{m}^{3}\right)\end{array}$ & $\begin{array}{c}\text { SP } \\
\left(\mathrm{kg} / \mathrm{m}^{3}\right)\end{array}$ & $\begin{array}{c}\text { Number of } \\
\mathrm{specimens}\end{array}$ \\
\hline Q0 & 0.45 & 355 & 0 & 640 & 1225 & 160 & 2.3 & 0.1 & 27 \\
Q20 & 0.45 & 355 & 245 & 640 & 980 & 160 & 2.3 & 0.1 & 27 \\
Q40 & 0.45 & 355 & 490 & 640 & 735 & 160 & 2.3 & 0.1 & 27 \\
Q60 & 0.45 & 355 & 735 & 640 & 490 & 160 & 2.3 & 0.1 & 27 \\
\hline
\end{tabular}

box, the surface moisture and laitance are dried, then the appearance damage of the specimen is checked and weighed, and the mass loss of the concrete specimen is analyzed by measurement:

$$
W=\frac{G_{0}-G_{n}}{G_{0}}
$$

where $W$ is the mass loss rate of the concrete specimen after each freeze-thaw cycle; $G_{0}$ is the initial mass of the concrete specimen $(\mathrm{kg})$; and $G_{n}$ is the mass of the concrete specimen after $n$ freeze-thaw cycles $(\mathrm{kg})$.

An NM-4B nonmetallic ultrasonic testing analyzer is used to measure the relative dynamic modulus. The specific measurement steps are as follows: (1) drying the surface moisture and laitance after the test piece is taken out, and placing it flat on the rubber pad so that it cannot be moved easily; (2) smearing the probe of nonmetallic ultrasonic testing instrument with vaseline and adjusting the instrument. The metal probe of the nonmetallic ultrasonic detector is placed in the center of the two-end faces of the prism and fixed; (3) the instrument sampling is started and the sampling line is adjusted so that the amplitude is between 3 and 5 , and the sampling reading is conducted after the waveform is stable. The test is repeated 3 times each time and the average value is taken as the test result of the test piece. The relative dynamic modulus of elasticity is calculated according to the following test [23]:

$$
E_{d x}=\frac{E_{d n}}{E_{d 0}}=\frac{S_{0}^{2}}{S_{n}^{2}}
$$

where $E_{d x}$ is the relative dynamic elastic modulus of the specimen (dimensionless), $E_{d n}$ is the dynamic elastic modulus of the specimen after $n$ times of freeze-thaw cycles $(\mathrm{MPa}), E_{d 0}$ is the dynamic elastic modulus of the specimen without freeze-thaw cycles $(\mathrm{MPa}), S_{n}$ is the super sound of the specimen after $n$ times of freeze-thaw cycles $(\mu \mathrm{s})$, and $S_{0}$ is the ultrasonic sound of the specimen without freeze-thaw cycles $(\mu \mathrm{s})$.

For the freeze-thaw test, when the relative dynamic elastic modulus of the specimen drops below $60 \%$ or the mass loss rate reaches $5 \%$, the test is terminated.

2.3.2. Compressive Strength Test. The compressive strength is measured by the YES-2000B digital display pressure tester. During every 50 freeze-thaw cycles, the specimen of $100 \mathrm{~mm} \times 100 \mathrm{~mm} \times 100 \mathrm{~mm}$ is taken out. After it dries naturally, the specimen is placed on the lower pressing plate of the tester, its center is aligned with the center of the lower pressing plate of the tester, and then the load is applied 
continuously and evenly. When the specimen is close to failure and starts to deform rapidly, the accelerator of the tester is not adjusted, and the failure load is recorded until the specimen fails. The compressive strength is determined according to the following test:

$$
F_{c u}=\frac{F}{A} \times 0.95 \text {, }
$$

where $F_{c u}$ is the cube compressive strength of the specimen $(\mathrm{MPa}), F$ is the compressive failure load of the specimen $(\mathrm{kN})$, and $A$ is the bearing area of the specimen.

For the compressive strength test, the arithmetic mean value of three specimens is taken as the compressive strength value of this group of specimens.

2.3.3. Capillary Water Absorption Test. The test was performed according to ASTM C1585, the standard test method for measuring the water absorption of hydraulic cement concrete [10], and the water absorption device is shown in Figure 1.

The capillary water absorption test adopts a cube of $100 \mathrm{~mm} \times 100 \mathrm{~mm} \times 100 \mathrm{~mm}$. Before the test, the epoxy resin shall be evenly coated on the four sides of the specimen (pouring surface as the upper surface) after standard curing for $28 \mathrm{~d}$. After the epoxy resin is dried, the specimen shall be baked in an oven (temperature: $105^{\circ} \mathrm{C}$, relative humidity: $80 \pm 3 \%$ ) for $48 \mathrm{~h}$ until the mass is constant, and then it shall be taken out. After the temperature of the specimen drops to room temperature, the upper surface of the specimen shall be sealed with plastic film to make one surface of the specimen contact with water. The length of each side of the contact surface between the specimen and water is measured using a vernier caliper and it is measured three times on each side, and the contact area is calculated. The specimen is placed on the support so that the liquid level is $1-3 \mathrm{~mm}$ higher than the bottom of the specimen. During the test, the specimen is weighed according to the time interval shown in Table 5 (time accuracy is $1 \mathrm{~s}$ ). The average value of the mass of each group of three specimens is taken, and the mass accuracy is $0.01 \mathrm{~g}$. The test interval was set as 25 freeze-thaw cycles because the durability of recycled concrete is poor, only $0,25,50$, and 75 freeze-thaw cycles are set.

\section{Results and Discussion}

3.1. Surface Deterioration. Concrete is a heterogeneous composite material. Therefore, the deterioration characteristics of freeze-thaw damage are closely related to the initial damage, such as microholes and microcracks [24]. During the whole freeze-thaw cycle, the surface degradation of recycled concrete can be divided into four stages, as shown in Figure 2:

Stage I: in the early stage of freeze-thaw, the surface of recycled concrete has basically no change, no damage, and no exposed aggregate, as shown in Figure 2(a).

Stage II: in the middle stage of freeze-thaw, at this time, the mortar on the surface of recycled concrete has

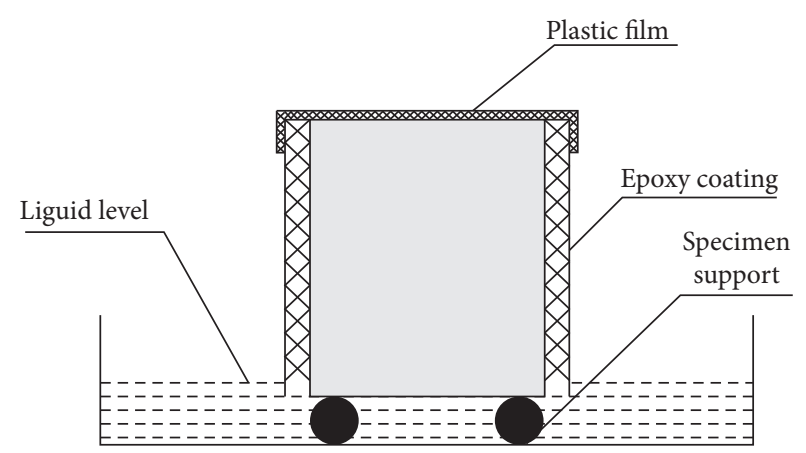

Figure 1: Capillary water absorption device diagram.

TABLE 5: Times and tolerances for the measurements schedule.

\begin{tabular}{lc}
\hline Time & Tolerance \\
\hline $60 \mathrm{~s}$ & $2 \mathrm{~s}$ \\
$5 \mathrm{~min}$ & $10 \mathrm{~s}$ \\
$10 \mathrm{~min}$ & $2 \mathrm{~min}$ \\
$20 \mathrm{~min}$ & $2 \mathrm{~min}$ \\
$30 \mathrm{~min}$ & $2 \mathrm{~min}$ \\
Every hour, up to $6 \mathrm{~h}$ & $2 \mathrm{~h}$ \\
Once a day, up to 3 days & $2 \mathrm{~h}$ \\
Day 4 to7, 3 measurements 24h apart & $2 \mathrm{~h}$ \\
Day 81 (one) measurement & $2 \mathrm{~h}$ \\
\hline
\end{tabular}

partial peeling off, forming a small number of holes, but the whole is relatively intact, as shown in Figure 2(b).

Stage III: :in the later stage of freeze-thaw cycle, the amount of mortar spalling on recycled concrete surface increases. With the increase of spalling amount, the exposed aggregate is gradually exposed, as shown in Figure 2(c).

Stage IV: in the freeze-thaw damage stage, at this time, with the number of freeze-thaw cycles approaching the limit of freeze-thaw damage times of the test piece, the mortar on the surface of the test piece is seriously spalling, the recycled coarse aggregate in the recycled concrete is obviously dropped, and the aggregate is completely exposed and damaged, as shown in Figure 2(d).

3.2. Mass. The change of mass loss rate of recycled concrete specimens with different replacement rates of recycled coarse aggregate in freeze-thaw environment is shown in Figure 3.

It can be seen from Figure 3 that with the increase of freeze-thaw cycles, the mass loss of recycled concrete decreases first and then increases. This is due to the existence of initial damage and microcracks inside the concrete in the early stage of freeze-thaw, which absorbs part of water and makes its quality increase. With the increase of freeze-thaw cycles, the internal cracks further expand and the amount of mortar peeling on the concrete surface gradually increases, resulting in the decrease of its quality. In the early stage of freeze-thaw, the mass loss of Q20 and Q40 is close to that of Q0. With the increase of freeze-thaw times, the loss rate of 


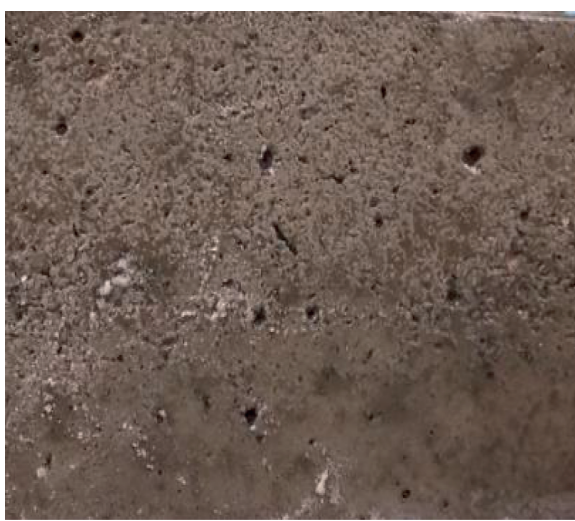

(a)

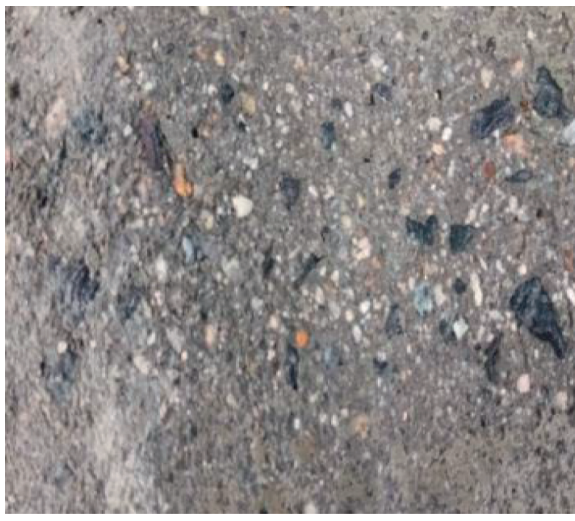

(c)

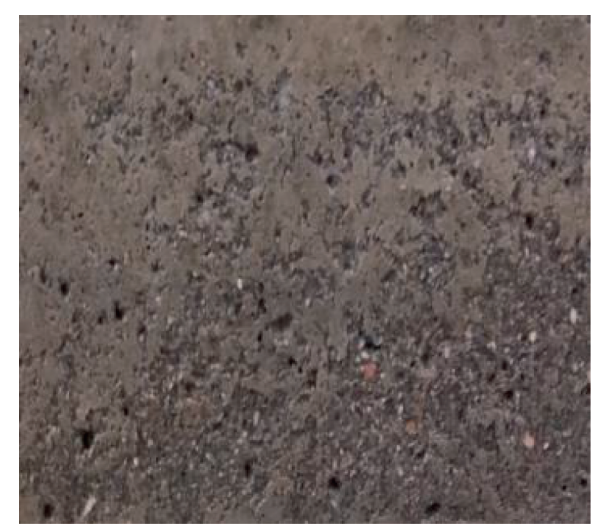

(b)

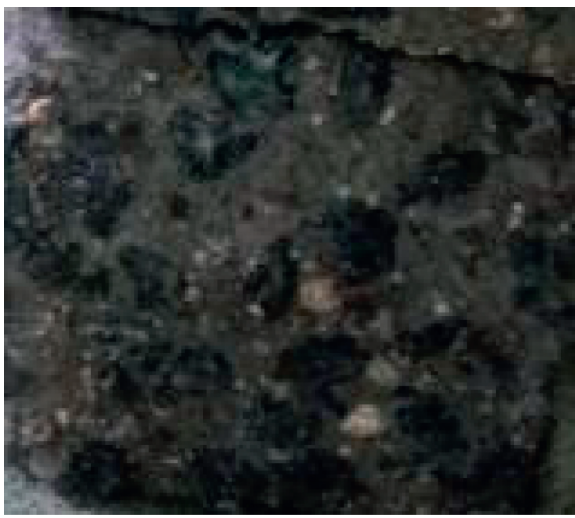

(d)

Figure 2: Concrete surface deterioration. (a) Pre freezing and thawing. (b) Mid freezing and thawing. (c) Late freeze-thaw. (d) Freeze-thaw damage.

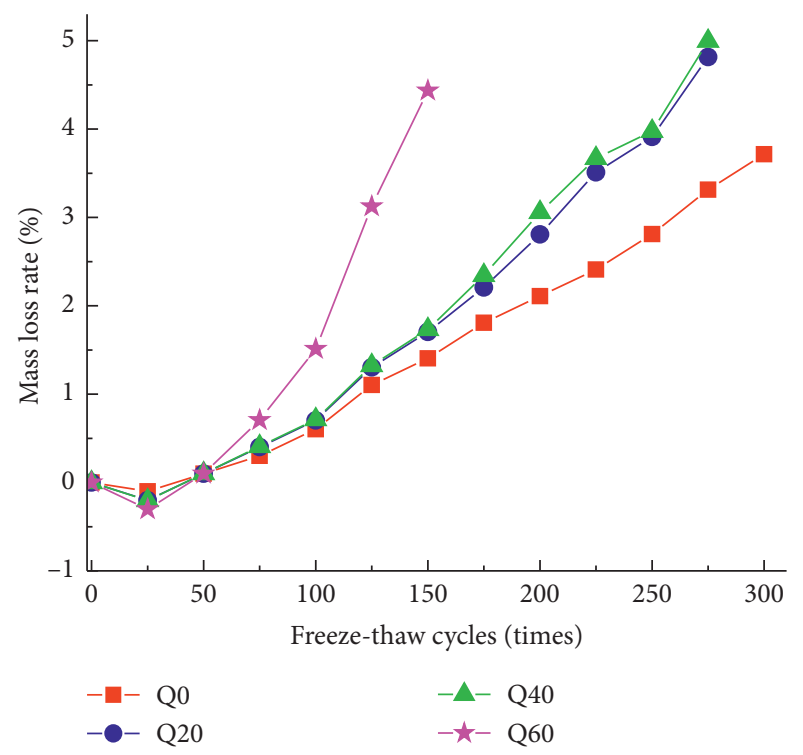

Figure 3: Mass loss rate.

Q20 and Q40 is gradually higher than that of Q0, but the loss trend of Q20 and Q40 is almost the same. After 300 cycles of freeze-thaw, the mass loss rate of the Q0 group was $3.71 \%$, while that of Q20 and Q40 groups was more than 5\%.
Therefore, the test of Q20 and Q40 groups was finished after 275 cycles of freeze-thaw. In the Q60 group, the mass loss rate of 175 times of freezing and thawing is more than $5 \%$, so the test is finished after 150 times of freezing and thawing. It can be seen that the replacement rate of recycled coarse aggregate has a great influence on the mass loss rate of the specimen, indicating that the recycled coarse aggregate plays a controlling role in the frost resistance of the specimen. The addition of recycled coarse aggregate accelerates the development of damage evolution and mortar peeling on the surface of the sample, which makes the quality loss more obvious.

3.3. Relative Dynamic Modulus of Elasticity. The change of relative dynamic elastic modulus of recycled concrete under freeze-thaw cycle is shown in Figure 4.

It can be seen from Figure 4 that the relative dynamic elastic modulus of four groups of concrete gradually decreases with the increase of freeze-thaw cycles, but the decline speed of Q20, Q40, and Q60 is significantly greater than that of Q0, which indicates that the addition of recycled coarse aggregate reduces the frost resistance of concrete, and the addition of different recycled coarse aggregates also has a great impact on its frost resistance. :Among them, the relative dynamic elastic modulus of Q60 group decreased the fastest, 


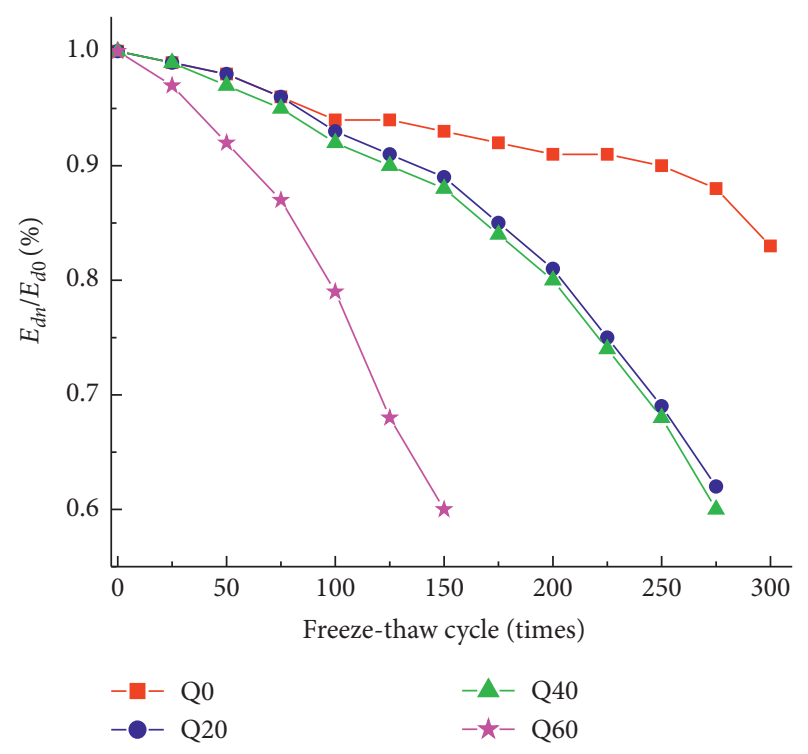

FIgURE 4: Relative dynamic elastic modulus.

while that of Q20 group and Q40 group decreased slowly. After 300 freeze-thaw cycles, the relative dynamic elastic modulus of the Q0 group changed little, only $17 \%$ was lost, and the specimens did not reach the freeze-thaw failure, while the relative dynamic elastic modulus of Q20 and Q40 groups decreased to $58.1 \%$ and $57.9 \%$, lower than $60 \%$, reaching the freeze-thaw failure condition. After 175 cycles of freeze-thaw, the relative dynamic modulus of elasticity of Q60 is $51.1 \%$, lower than $60 \%$, reaching the condition of freeze-thaw failure. It can be seen that the frost resistance of Q20 and Q40 groups are similar. From the economic point of view, the concrete with $40 \%$ recycled coarse aggregate is the best.

3.4. Compressive Strength. The change rule of compressive strength of recycled concrete with different replacement rates of recycled coarse aggregate under freeze-thaw cycle is shown in Figure 5.

It can be seen from Figure 5 that the compressive strength of Q20, Q40, and Q60 groups is not significantly lower than that of the Q0 group before freeze-thaw, and the compressive strength of Q20 and Q40 groups is even higher than that of the Q0 group. With the increase of freeze-thaw cycles, the compressive strength of four groups of concrete gradually decreased, and the loss rate of compressive strength of Q20, Q40, and Q60 groups was significantly higher than that of Q0. With the same freeze-thaw cycles, the higher the replacement rate of recycled coarse aggregate, the lower the strength and the higher the strength loss rate. The reasons for the abovementioned phenomenon are as follows: although the strength of recycled coarse aggregate is lower than that of natural stone [25], the water absorption of recycled coarse aggregate is higher, the water cement ratio between aggregate and mortar interface is lower, and the density of cement slurry around recycled coarse aggregate is higher. Therefore, before the freeze-thaw cycle, the overall strength of the specimen did not decrease significantly. With the increase of freeze-thaw cycles, the damage accumulated and the compressive strength decreased.

3.5. Water Absorption Performance. According to the test results and the change of the mass of the concrete specimen in a certain time $(t)$, the cumulative water absorption $I(\mathrm{~mm})$ on the unit cross-sectional area can be obtained by using the following formula:

$$
I=\frac{m_{t}}{A \rho} .
$$

where $m_{t}$ is the mass difference before and after water absorption of the specimen (g); $A$ is the contact area between the specimen and water $\left(\mathrm{mm}^{2}\right)$; and $\rho$ is the density of water $\left(\mathrm{g} / \mathrm{mm}^{3}\right)$. When the hydration reaction is neglected, the cumulative water absorption of one-dimensional capillary water absorbing concrete in a certain period of time is [26]

$$
I=S \sqrt{t}+b,
$$

where $S$ is the water absorption rate of porous material in contact with water, which is obtained by linear fitting of the cumulative water absorption curve, and $b$ is the intercept on the number axis of the curve, which is caused by the rapid filling of the instantaneous capillary pores on the surface of the specimen in contact with water.

3.5.1. Cumulative Water Absorption Curve. After 0, 25, 50, and 75 times freeze-thaw, the water absorption of the RAC specimen was measured, and the water absorption of the RAC specimen in a certain period of time was obtained. Under the action of freeze-thaw cycle, the cumulative water absorption of recycled concrete specimens with different replacement rates of recycled coarse aggregate changes with the square root of time as shown in Figure 6.

It can be seen from Figure 6 that the cumulative water absorption process of concrete increases nonlinearly with the square root of time and increases rapidly in the early stage $\left(T^{1 / 2}=0-147 \mathrm{~s}\right)$ and slowly in the middle stage $\left(T^{1 / 2}=147-518 \mathrm{~s}\right)$ and tends to be gentle until equilibrium in the later stage $\left(T^{1 / 2}=518-831 \mathrm{~s}\right)$. Under the same freezethaw environment, the water absorption of recycled concrete is significantly higher than that of ordinary concrete, and the cumulative water absorption is positively related to the replacement rate of recycled coarse aggregate. In the three stages, the cumulative water absorption increased linearly, but the growth rate decreased gradually, showing that the initial capillary water absorption rate was faster, the middle capillary water absorption rate was slower, and the later capillary water absorption rate was basically unchanged. This is due to the capillary water absorption of concrete at the initial stage, which makes the gap between the bottom and the water contact area absorb water rapidly, and the water quickly fills the internal connection gap of concrete. With the extension of water absorption time, the depth of water absorption increases, the surface concrete gradually reaches the water saturation, the internal concrete keeps dry, and the water invades continuously through the internal and external humidity gradient, but the capillary adsorption 


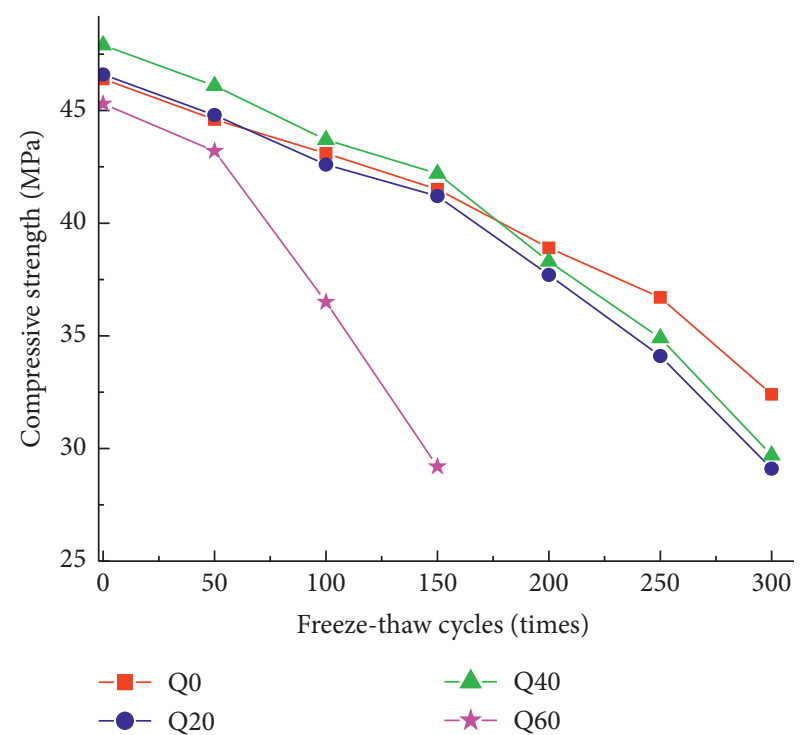

(a)

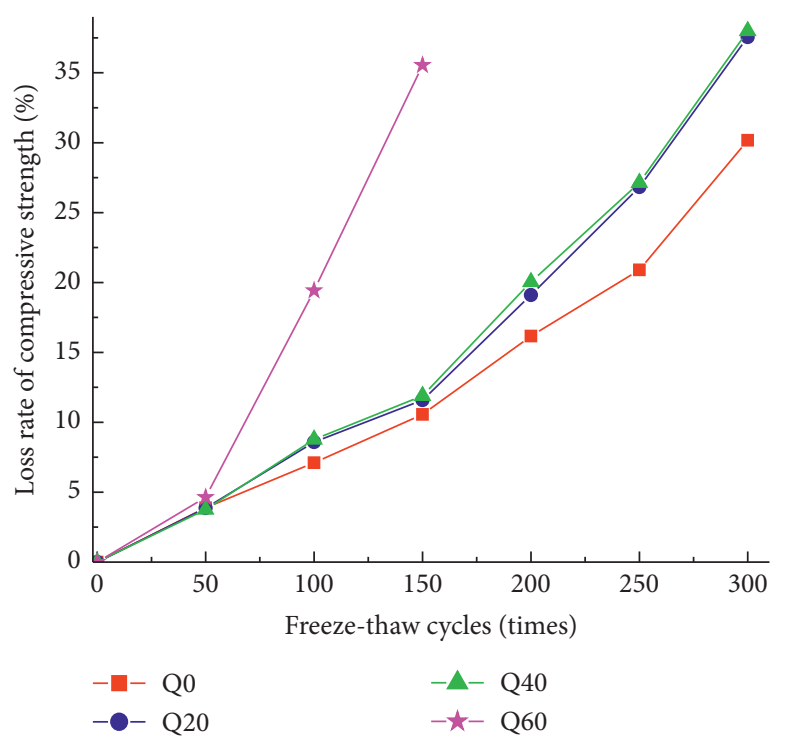

(b)

Figure 5: (a) Compressive strength. (b) Loss rate of compressive strength.

force decreases gradually, and the water absorption rate slows down. It can be seen from Figure 6(d) that the accumulated water absorption of Q20 is more than that of Q40 at 75 freeze-thaw cycles, which is caused by the small number of samples, the small size of test pieces, and the uneven distribution of coarse aggregate. The cumulative water absorption of recycled concrete with the same replacement rate of recycled coarse aggregate increases with the increase of freeze-thaw cycles.

3.5.2. Relationship between Capillary Water Absorption and Freeze-Thaw Cycle Times. According to the relation curve in Figure 6, the initial water absorption, secondary water absorption, and later water absorption of each group of test pieces can be obtained by fitting formula (5) [10]. Figure 7 shows the change rule of capillary water absorption with the number of freeze-thaw cycles, in which $S_{I}$ is the initial capillary water absorption, $S_{S}$ is the secondary capillary water absorption, and $S_{F}$ is the later capillary water absorption.

Figure 7(a) shows that with the increase of freeze-thaw cycles, the initial capillary water absorption of recycled concrete increases, and the larger the replacement rate of recycled coarse aggregate is, the faster the initial capillary water absorption of recycled concrete increases. The trend of change of initial capillary water absorption of Q20, Q40, and Q60 is basically the same. When the freeze-thaw cycle is 75 times, compared with that before the freeze-thaw cycle, the initial capillary water absorption of the three is basically the same. The maximum increase of water rate is three times. It can be seen that the internal damage of concrete caused by freeze-thaw cycle significantly increases the initial capillary water absorption of recycled concrete. Under the number of freeze-thaw cycles in this test, the initial capillary water absorption of ordinary concrete has no significant effect on the freeze-thaw cycle.

It can be seen from Figure 7(b) that the change rule of secondary capillary water absorption of recycled concrete is completely different from that of ordinary concrete. The secondary capillary water absorption of recycled concrete is negatively related to the number of freeze-thaw cycles, while the secondary capillary water absorption of ordinary concrete is positively related to the number of freeze-thaw cycles. Before the freeze-thaw cycle, the secondary capillary water absorption of Q60 is smaller than that of Q20 and Q40. This is because the internal structure of Q60 has not been damaged, and its initial capillary water absorption is large, which makes the secondary capillary water absorption decrease. With the increase of freeze-thaw cycle times, the second capillary water absorption decreased in the form of quadratic curve. The second capillary water absorption of Q20, Q40, and Q60 decreased 86.7\%, 77.8\%, and 70.9\%, respectively, when the freeze-thaw cycle was 75 times than when the freeze-thaw cycle was not. The second capillary water absorption of Q60 decreased less than that of Q20 and Q40, indicating that the larger the replacement rate of recycled coarse aggregate, the more the water absorption. For Q0, with the increase of freeze-thaw cycle times, the second capillary water absorption increases linearly. When the freeze-thaw cycle is 75 times, the capillary water absorption increases $73.6 \%$ compared with that without freezethaw cycle. After 50 freeze-thaw cycles, the second capillary water absorption of Q0 is greater than Q20, Q40, and Q60, which shows that the second capillary water absorption of Q0 has a strong effect on the freeze-thaw cycle.

It can be seen from Figure 7(c) that when the number of freeze-thaw cycles is small, the capillary water absorption of Q0, Q20, Q40, and Q60 increases slightly in the later period. When the number of freeze-thaw cycles reaches a certain 


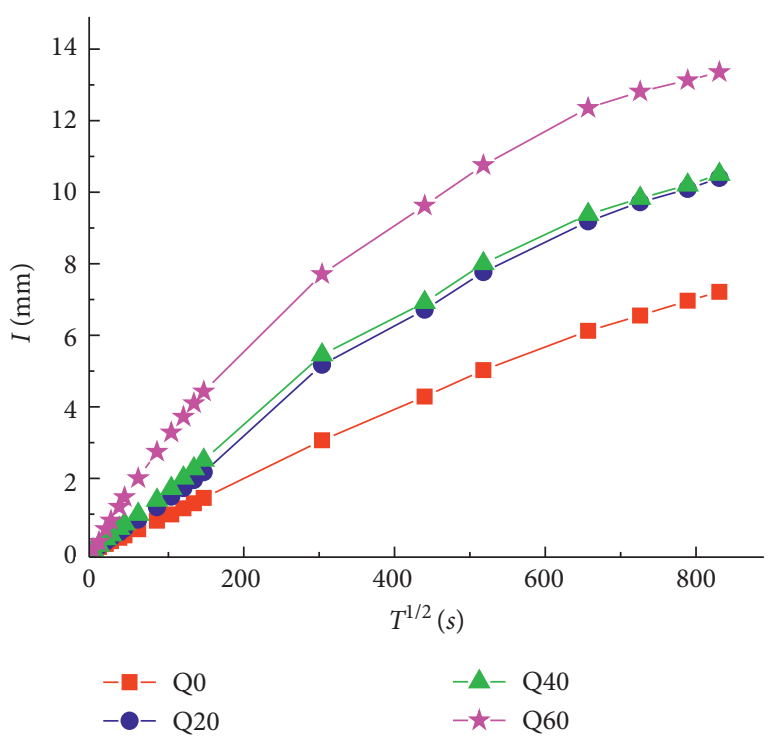

(a)

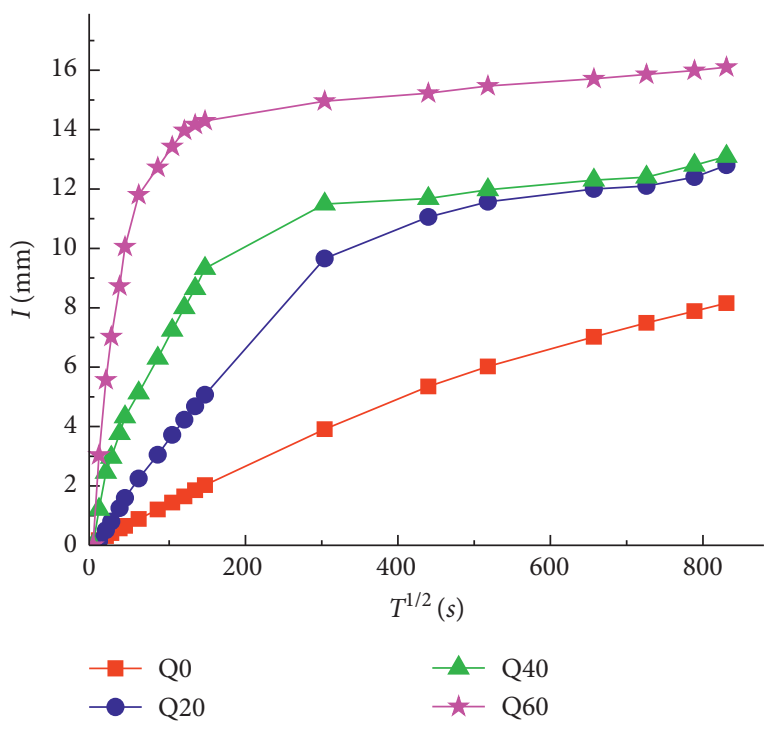

(c)

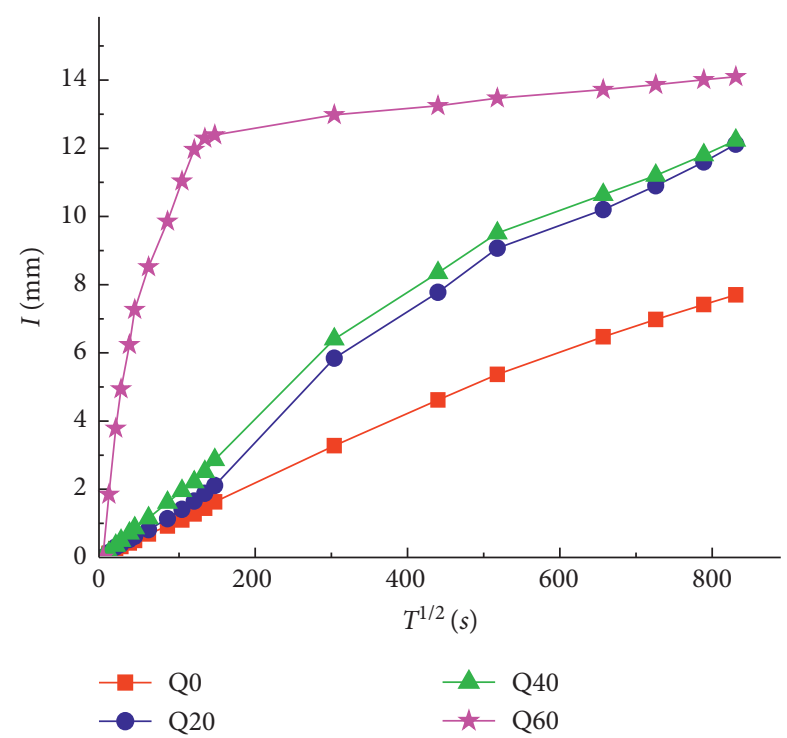

(b)

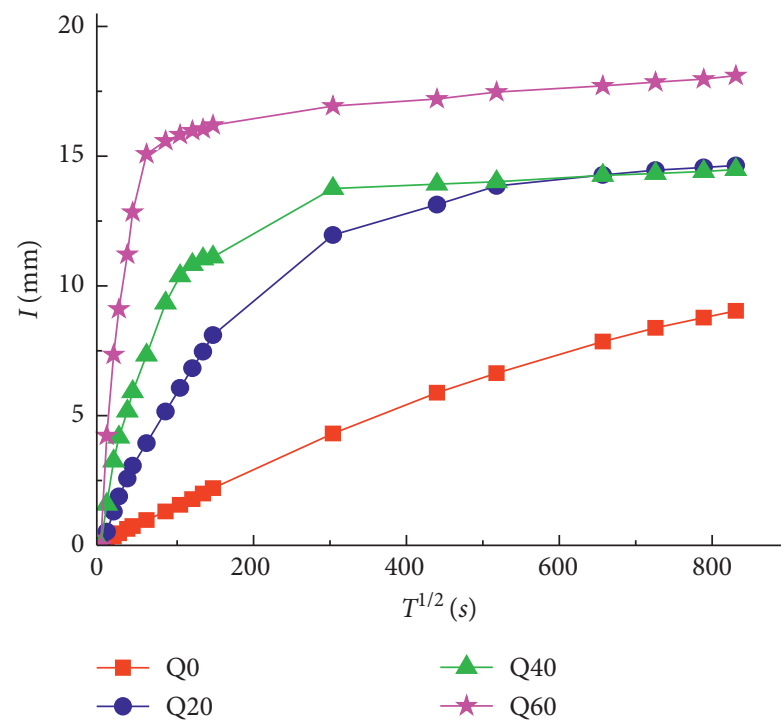

(d)

FIgURE 6: The curve of cumulative water absorption with the square root of time. (a) Freeze-thaw cycles of 0. (b) Freeze-thaw cycles of 25. (c) Freeze-thaw cycles of 50. (d) Freeze-thaw cycles of 75.

number, the capillary water absorption of the four groups of test pieces suddenly decreases in the later period and then tends to be stable. For Q20, Q40, and Q60, when the number of freeze-thaw cycles is 25 , the capillary water absorption will increase slightly in the later period, and then it begins to decrease. When the freeze-thaw cycle reaches 50 times, the capillary water absorption at the later stage is basically unchanged, and the curve tends to be gentle; for Q0, when the freeze-thaw cycle reaches 50 times, the capillary water absorption at the later stage gradually increases. After that, it began to decline. It is predicted that the capillary water absorption rate of Q0 will not change with the increase of freeze-thaw cycle times in the later period, and the curve will tend to be gentle. It can be seen that the capillary water absorption rate in the later period can be used as an index to evaluate the service life of concrete. From the abovementioned analysis, it can be seen that the freeze-thaw cycle has a significant impact on the capillary water absorption performance of recycled concrete, as shown in its initial stage. The capillary water absorption increases greatly, and with the increase of freeze-thaw cycle times, the initial capillary water absorption will become larger and larger, which will make the recycled concrete suffer a large number of water and aggressive media (such as chloride and sulfate) invasion in a short time, thus aggravating the deterioration and damage.

3.5.3. Relationship between Initial Capillary Water Absorption and Freeze-Thaw Damage. In this paper, the relative 


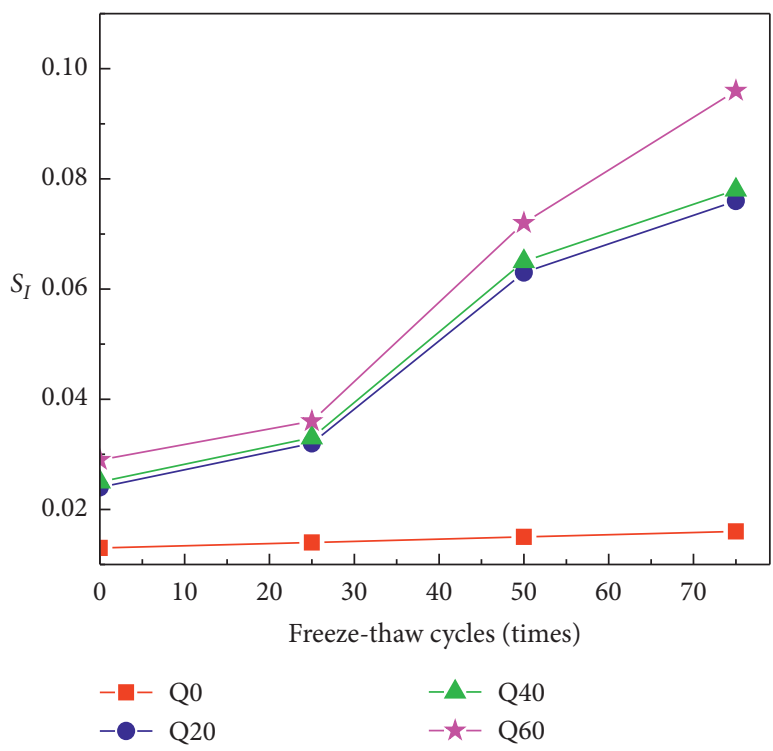

(a)

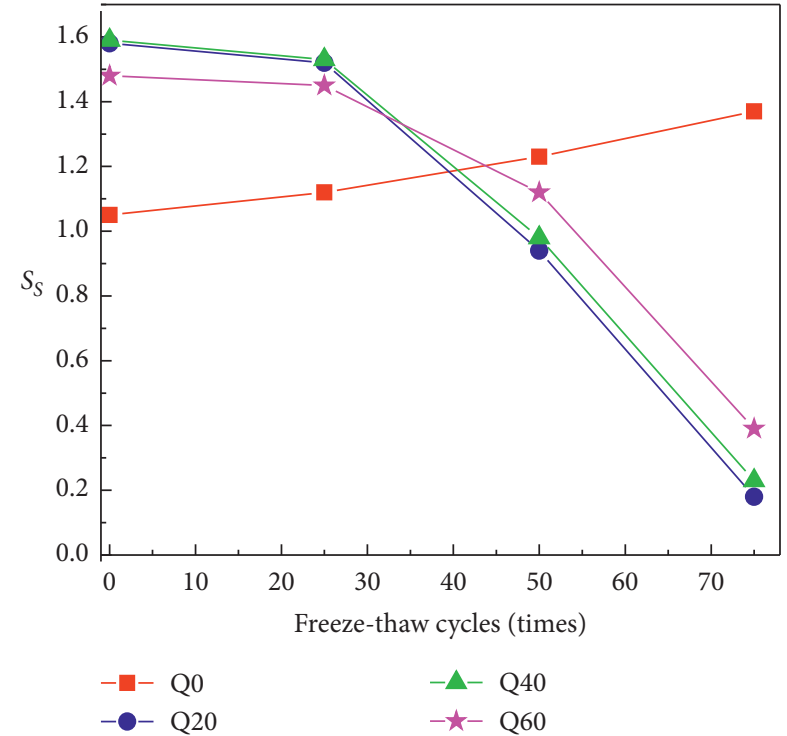

(b)

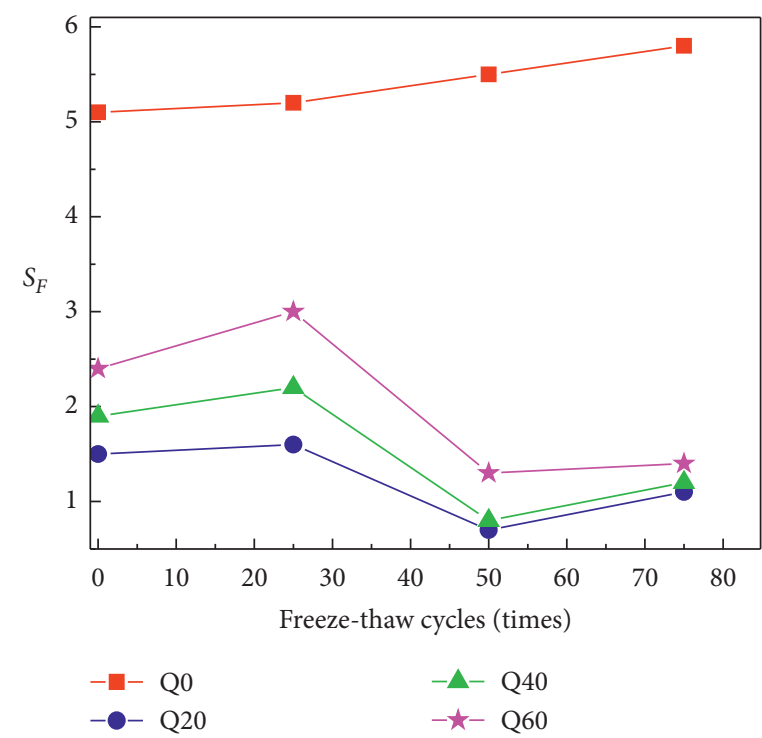

(c)

FIGURE 7: Change of capillary water absorption with freeze-thaw cycle. (a) Initial water absorption. (b) Secondary water absorption. (c) Late water absorption.

dynamic elastic modulus of recycled concrete with different replacement rates of recycled coarse aggregate in freeze-thaw environment is taken as the damage variable, the ratio of initial capillary water absorption to relative dynamic elastic modulus $\left(S_{I} / E_{r}\right)$ is used to analyze the frost resistance of recycled concrete specimens, and the relationship curve between $S_{I} / E_{r}$ and the number of freeze-thaw cycles is established, as shown in Figure 8. The expression of the freeze-thaw damage value under freeze-thaw cycle is as follows:

$$
D_{n}=1-\frac{E_{n}}{E_{0}}
$$

where $D_{n}$ is the damage value of recycled concrete under different freeze-thaw cycles; $E_{n}$ is the relative dynamic elastic modulus of recycled concrete under different freeze-thaw cycles; $E_{0}$ is the relative dynamic elastic modulus of recycled concrete before freeze-thaw; and $n$ is the number of freezethaw cycles.

It can be seen from Figure 8 that with the increase of freeze-thaw cycles, $S_{I} / E_{r}$ increases continuously, and the $S_{I} /$ $E_{r}$ growth rate of recycled concrete is faster than that of ordinary concrete. When Q0, Q20, Q40, and Q60 were frozen and thawed 75 times, $S_{I} / E_{r}$ increased 1.2, 3.5, 4.1, and 5 times than that of unfrozen $S_{I} / E_{r}$, respectively. It can be seen that the freeze-thaw cycle has a great influence on the 


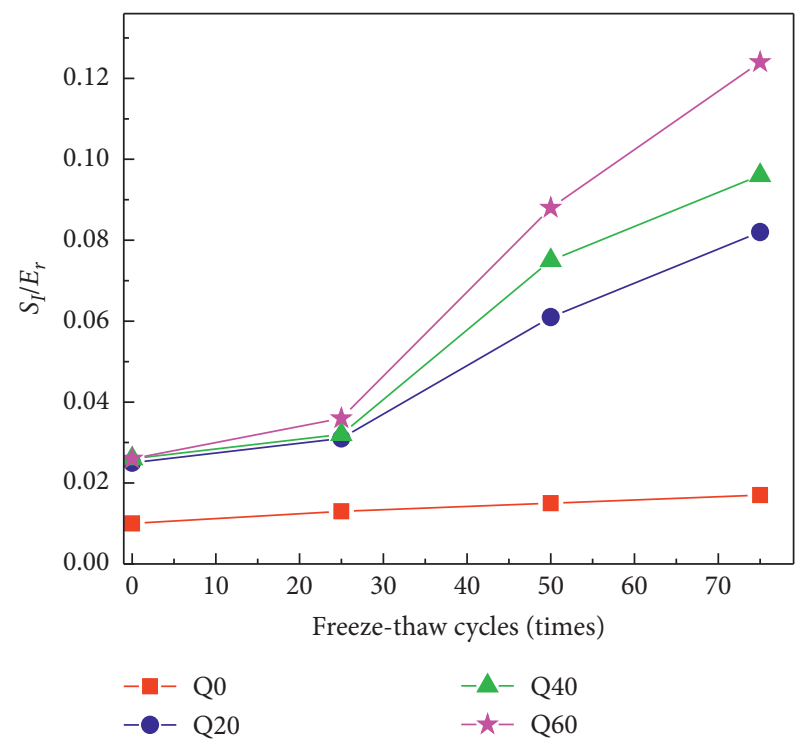

FIgURE 8: Variation of $S_{I} / E_{r}$ with freeze-thaw cycles.

$S_{I} / E_{r}$ of recycled concrete, and the more the number of freeze-thaw cycles, the greater the $S_{I} / E_{r}$, the greater the initial capillary water absorption, the smaller the relative dynamic elastic modulus, and the worse the frost resistance.

\section{Establishment of Prediction Model of Initial Capillary Water Absorption of RAC in Freeze- Thaw Environment}

Because the initial capillary water absorption can reflect the capillary water absorption of concrete under freeze-thaw damage, the prediction model of the initial capillary water absorption of recycled concrete under freeze-thaw environment is considered. Taking the freeze-thaw failure and recycled coarse aggregate content as variables, the freezethaw failure characteristics of recycled concrete are established.

Basic assumptions: (1) the water absorption process is one-dimensional, without considering the influence of chemical reaction, evaporation, and other factors after each group of materials encounter water; (2) the recycled concrete specimen is initially in a completely dry state, and the boundary conditions are stable during the water absorption process; (3) the initial capillary water absorption is only a function of the number of freeze-thaw cycles, without considering the temperature of freeze-thaw cycles and the impact of external environmental conditions; (4) with the increase of freeze-thaw cycles, the initial capillary water absorption increased, and all of them were positive.

The basic form of the prediction model of the initial capillary water absorption of recycled concrete refers to the relationship curve between the initial capillary water absorption and the number of freeze-thaw cycles in Figure 7 (a). Through various forms of fitting, it is found that the changes of the initial capillary water absorption and the number of freeze-thaw cycles of recycled concrete follow the exponential distribution. Therefore, the basic form of the
TABle 6: Parameter fitting.

\begin{tabular}{lccc}
\hline Signs & $A$ & $B$ & $R^{2}$ \\
\hline Q0 & 1.28 & 0.31 & 0.999 \\
Q20 & 0.14 & 0.004 & 0.954 \\
Q40 & 0.15 & 0.004 & 0.951 \\
Q60 & 0.05 & 0.012 & 0.969 \\
\hline
\end{tabular}

TABLE 7: Comparison between the trial value and calculated value.

\begin{tabular}{lcccc}
\hline & \multicolumn{4}{c}{ Number of freeze-thaw cycles (times) } \\
& 0 & 25 & 50 & 75 \\
\hline Trial value (TA) & 0.0249 & 0.0334 & 0.0652 & 0.0783 \\
Calculated value (CA) & 0.0242 & 0.0351 & 0.0663 & 0.0801 \\
TA/CA & 1.029 & 0.952 & 0.983 & 0.977 \\
\hline
\end{tabular}

prediction model of the initial capillary water absorption of recycled concrete under the freeze-thaw environment is established. The form is

$$
S_{I}=A \times B^{N}
$$

where $S_{I}$ is the initial capillary water absorption; $A$ and $B$ are the influence coefficients of the replacement rate of recycled coarse aggregate; $N$ is the number of freeze-thaw cycles; and $R^{2}$ is the regression coefficient. The fitting parameters are shown in Table 6.

4.1. Establishment of Prediction Model. According to the test data, the regression analysis of the initial capillary water absorption of Q20 and Q60 samples under the freeze-thaw environment is carried out, and the relationship between the influence coefficient of the replacement rate of recycled coarse aggregate and the replacement rate of recycled coarse aggregate is obtained as follows:

$$
\begin{aligned}
& A=1.18 \times e^{-16.13 \mu}, \\
& B=0.3 \times e^{-161.6 \mu},
\end{aligned}
$$

where $\mu$ is the replacement rate of recycled coarse aggregate and $\mu \neq 0$.

According to the abovementioned analysis, substituting $A$ and $B$ into formula (6), the prediction model of the initial capillary water absorption of recycled concrete in freezethaw environment can be obtained as follows:

$$
S_{I}=1.18 \times e^{-16.13 \mu} \times\left(0.3 \times e^{-161.6 \mu}\right)^{N} .
$$

4.2. Validation of Prediction Model. According to the test results, the test data of the Q40 specimen is used to verify the prediction model of initial capillary water absorption established in this paper. The test value of Q40 initial capillary water absorption and the calculated value of the prediction model under different freeze-thaw environments are shown in Table 7, and the relationship between the test value and the calculated value of the prediction model is shown in Figure 9. 


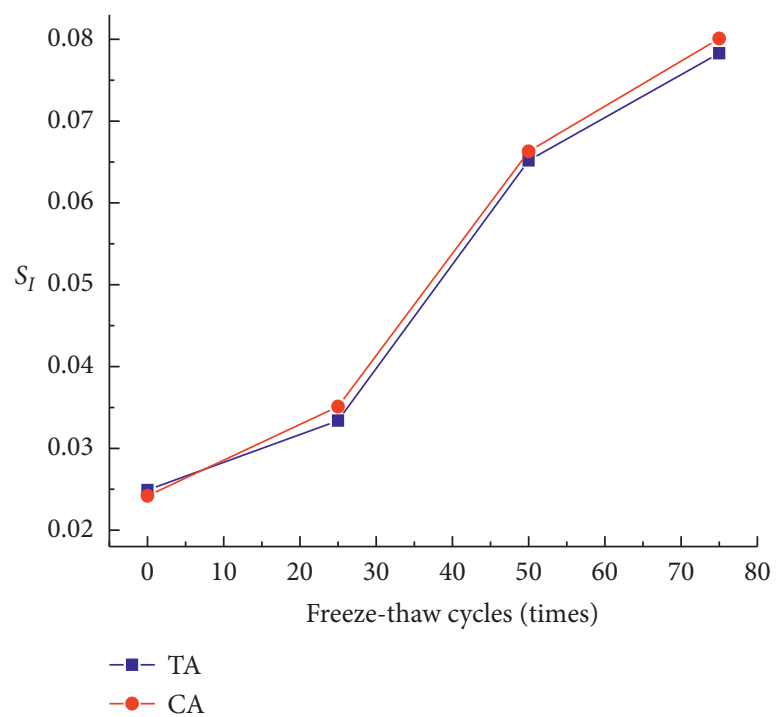

Figure 9: Relationship of test values and calculation values.

The average value of the ratio of the initial capillary water absorption test value of the Q40 group to the calculated value of the model is 0.98525 , and the standard deviation is 0.007 . It can be seen from Table 6 that the prediction model has high accuracy.

\section{Conclusion}

(1) With the increase of freeze-thaw cycles, the frost resistance of recycled concrete decreases gradually, but the decreasing range is different. The content of recycled coarse aggregate also has a great influence on the frost resistance of concrete. The frost resistance of concrete with $20 \%$ recycled coarse aggregate and $40 \%$ recycled coarse aggregate is very similar. From the economic point of view, the concrete with $40 \%$ recycled coarse aggregate is the best.

(2) The cumulative water absorption curve of recycled concrete and ordinary concrete increases linearly in three stages, but the change trend of the initial capillary water absorption curve is not the same. With the increase of freeze-thaw cycles, the initial capillary water absorption curve of recycled concrete and ordinary concrete increases in the form of a firstorder function; the secondary capillary water absorption curve of recycled concrete decreases in a second-order function, while the secondary capillary water absorption curve of ordinary concrete rises in a first-order function; the later capillary water absorption curve of recycled concrete and ordinary concrete first rises steadily. After rising, it suddenly dropped and finally stabilized.

(3) The capillary water absorption capacity of recycled concrete is better than that of ordinary concrete. In the same freeze-thaw environment, the cumulative water absorption and initial capillary water absorption of recycled concrete are greater than that of ordinary concrete. Therefore, the influence of freezethaw environment on the durability of recycled concrete should be fully considered in a cold area.

(4) With the same replacement rate of recycled coarse aggregate, the more the freeze-thaw cycles, the stronger the capillary water absorption performance of recycled concrete. This is because the freeze-thaw cycle aggravates the damage of recycled concrete and then increases the initial capillary water absorption of recycled concrete.

(5) According to the test results, the prediction model of water absorption of recycled concrete in the early stage of freeze-thaw damage was established with the replacement rate of recycled coarse bone and freezethaw damage as variables. The experimental results are in good agreement with the model results, which can provide a reference for the study of frost resistance of recycled concrete.

\section{Data Availability}

The data used to support the findings of this study are included within the article.

\section{Conflicts of Interest}

The authors declare that they have no conflicts of interest regarding the publication of this paper.

\section{Acknowledgments}

This research was supported by the National Natural Science Foundation Youth Project of China (Grant no. 51508461) and the Basic Research Program of Shanxi Natural Science (Grant no. 2018JQ521). The authors would like to express special appreciation to the National Natural Science Foundation of China and Shanxi Natural Science.

\section{References}

[1] J. Xiao, J. Li, and L. Yang, "The latest development and review on the technology of recycled co," Concrete, vol. 25, no. 10, pp. 17-20, 2003.

[2] D. Foti and D. Cavallo, "Mechanical behavior of concretes made with non-conventional organic origin calcareous aggregates," Construction and Building Materials, vol. 179, pp. 100-106, 2018.

[3] S. Li, G. Chen, G. Ji, and Y. Lu, "Quantitative damage evaluation of concrete suffered freezing-thawing by DIP technique," Construction and Building Materials, vol. 69, pp. 177-185, 2014.

[4] B. Huang and C. Qian, "Capillary water absorption of admixture concrete," Concrete and Cement Products, vol. 35, no. 4, pp. 14-16, 2008.

[5] J. A. Rossignolo and M. V. C. Agnesini, "Durability of polymer-modified lightweight aggregate concrete," Cement and Concrete Composites, vol. 26, no. 4, pp. 375-380, 2004.

[6] C. Tasdemir, "Combined effects of mineral admixtures and curing conditions on the sorptivity coefficient of concrete," Cement and Concrete Research, vol. 33, no. 10, pp. 1637-1642, 2003. 
[7] M. H. F. Medeiros and P. Helene, "Surface treatment of reinforced concrete in marine environment: influence on chloride diffusion coefficient and capillary water absorption," Construction and Building Materials, vol. 23, no. 3, pp. 1476-1484, 2009.

[8] J. Qiu, P. Guo, M. Xing, X. Guan, and G. Xiong, "Study on capillary water absorption properties of polypropylene fibre coal gangue ceramsite concrete under freeze-thaw damage," The Journal of Engineering, vol. 2020, no. 3, pp. 98-103, 2020.

[9] F. Ghasemzadeh, R. Rashetnia, D. Smyl, and M. Pour-Ghaz, "A comparison of methods to evaluate mass transport in damaged mortar," Cement and Concrete Composites, vol. 70, pp. 119-129, 2016.

[10] ASTM C1585-13, Standard Test Method for Measurement of Rate of Absorption of Water by Hydraulic Cement Concretes, ASTM, West Conshohocken, PA, USA, 2004.

[11] E. Elawady, A. A. E. Hefnawy, and R. A. F. Ibrahim, "Comparative study on strength, permeability and sorptivity of concrete and their relation with concrete durability," International Journal of Engineering and Innovative Technology (IJEIT), vol. 4, no. 4, pp. 132-139, 2014.

[12] D. Foti, M. Lerna, M. Sabbà, and V. Vacca, "Mechanical characteristics and water absorption properties of blast-furnace slag concretes with fly ashes or microsilica additions," Applied Sciences, vol. 9, no. 7, pp. 1279-1292, 2019.

[13] X. Ding, P. Zhang, and Q. Liu, "Migration of water and chloride ions in recycled concrete," Concrete and Cement Products, vol. 45, no. 9, pp. 32-35, 2018.

[14] H. Wan, Z. Lin, and S. He, "The mechanism and model of water diffusion in recycled concrete," Journal of Wuhan University of Technology, vol. 25, no. 12, pp. 103-107, 2003.

[15] Y. Guo, Study on Dry Shrinkage Properties of Recycled Aggregate/Cement Composites, Kunming University of Science and Technology, Kunming, China, 2010.

[16] S. Han, Q. Li, and G. Yue, "Effects of recycled coarse aggregate quality and substitution rate on chloride ion penetration resistance of recycled concrete," Concrete, vol. 37, no. 12, pp. 80-83, 2015.

[17] F. Tittarelli, M. Carsana, and M. L. Ruello, "Effect of hydrophobic admixture and recycled aggregate on physicalmechanical properties and durability aspects of no-fines concrete," Construction and Building Materials, vol. 66, no. 1, pp. 30-37, 2014.

[18] H. Wu, Experimental Research on Impermeability of Modified Recycled Concrete, Hefei University of Technology, Hefei, China, 2013.

[19] Z. Jiang, "Deterioration mechanism of concrete pore structure under freeze-thaw cycles," Journal of HuaQiao University (Natural Science), vol. 36, no. 6, pp. 716-720, 2015, in Chinese.

[20] T. Gonen, S. Yazicioglu, and B. Demirel, "The influence of freezing-thawing cycles on the capillary water absorption and porosity of concrete with mineral admixture," KSCE Journal of Civil Engineering, vol. 19, no. 3, pp. 667-671, 2015.

[21] DG/T J08-2018-2007, Technical Code for Application of Recycled Concrete, Shanghai Construction and Transportation Commission, Shanghai, China, 2007.

[22] GB 50082-2009, Standard for Test Methods of Long-Term Performance and Durability of Ordinary Concrete, China Architecture and Building Press, Beijing, China, 2010.

[23] CECS 21:2000, Technical Code for Ultrasonic Testing of Concrete Defects, China Planning Press, Beijing, China, 2000.

[24] W. Tian, Y. Xie, and F. Dang, "Experiment and damage evolution of mechanical properties of concrete under freezing and thawing environment," Journal of Sichuan University:
Engineering Science Edition, vol. 47, no. 4, pp. 38-44, 2015, in Chinese.

[25] Q. Li, H. Quan, and Y. Qin, Recycled Aggregate for Concrete, China Construction Industry Press, Beijing, China, 2011.

[26] C. Hall, "Water sorptivity of mortars and concretes: a review," Magazine of Concrete Research, vol. 41, no. 147, pp. 51-61, 1989. 